\title{
Manual and Electroacupuncture for Labour Pain: Study Design of a Longitudinal Randomized Controlled Trial
}

\author{
Linda Vixner, ${ }^{1,2}$ Lena B. Mårtensson, ${ }^{3,4}$ Elisabet Stener-Victorin,, ${ }^{5,6}$ and Erica Schytt ${ }^{1,7}$ \\ ${ }^{1}$ Division of Reproductive Health, Department of Women's and Children's Health, Karolinska Institutet, Retzius väg 13A, \\ 17177 Stockholm, Sweden \\ ${ }^{2}$ School of Health and Social Studies, Dalarna University, Högskolan Dalarna, 79188 Falun, Sweden \\ ${ }^{3}$ School of Life Sciences, University of Skövde, P.O. Box 408, 54128 Skövde, Sweden \\ ${ }^{4}$ College of Nursing, University of Rhode Island, White Hall, 2 Heathman Road, Kingston, RI 02881-2021, USA \\ ${ }^{5}$ Institute of Neuroscience and Physiology, Department of Physiology, Sahlgrenska Academy, University of Gothenburg, \\ 40530 Gothenburg, Sweden \\ ${ }^{6}$ Department of Obstetrics and Gynecology, First Affiliated Hospital, Heilongiiang University of Chinese Medicine, \\ Harbin 150040, China \\ ${ }^{7}$ Centre for Clinical Research Dalarna, Nissers väg 3, 79182 Falun, Sweden
}

Correspondence should be addressed to Linda Vixner, linda.vixner@ki.se

Received 27 January 2012; Revised 10 February 2012; Accepted 12 February 2012

Academic Editor: Gerhard Litscher

Copyright ( 2012 Linda Vixner et al. This is an open access article distributed under the Creative Commons Attribution License, which permits unrestricted use, distribution, and reproduction in any medium, provided the original work is properly cited.

\begin{abstract}
Introduction. Results from previous studies on acupuncture for labour pain are contradictory and lack important information on methodology. However, studies indicate that acupuncture has a positive effect on women's experiences of labour pain. The aim of the present study was to evaluate the efficacy of two different acupuncture stimulations, manual or electrical stimulation, compared with standard care in the relief of labour pain as the primary outcome. This paper will present in-depth information on the design of the study, following the CONSORT and STRICTA recommendations. Methods. The study was designed as a randomized controlled trial based on western medical theories. Nulliparous women with normal pregnancies admitted to the delivery ward after a spontaneous onset of labour were randomly allocated into one of three groups: manual acupuncture, electroacupuncture, or standard care. Sample size calculation gave 101 women in each group, including a total of 303 women. A Visual Analogue Scale was used for assessing pain every 30 minutes for five hours and thereafter every hour until birth. Questionnaires were distributed before treatment, directly after the birth, and at one day and two months postpartum. Blood samples were collected before and after the first treatment. This trial is registered at ClinicalTrials.gov: NCT01197950.
\end{abstract}

\section{Introduction}

Methodology problems in acupuncture research have previously been highlighted [1], including the area of labour pain [2]. A recent systematic review [2] concludes that further high-quality studies are needed as the findings from existing studies [3-9] on the effect of acupuncture on labour pain are contradictory and difficult to interpret for a number of methodology reasons.

One such reason is that the studies have different primary outcomes. In total, seven randomized controlled trials (RCTs) were published in this area of research between 2002 and 2009. Of them, six trials report the women's subjective assessment of labour pain intensity as a primary outcome measure [4-9]. Two studies found that acupuncture was more effective than low-intensity "minimal acupuncture" at nonacupuncture points $[6,8]$. On the other hand, three studies found no difference in pain intensity between women receiving acupuncture and women receiving standard care only $[4,7,9]$ or with the addition of transcutaneous electrical nerve stimulation (TENS) [4] or administering acupuncture at nonacupuncture points [7]. A further study showed that sterile water injections reduced the intensity of labour pain more effectively than acupuncture [5] and that this effect is most likely mediated via similar mechanisms to highintensity acupuncture (where needles are more frequently stimulated). 
In two studies, the primary outcome was the use of pharmacological pain relief, where women who received acupuncture treatment used epidural analgesia and/or pethidine to a lesser extent than women who received standard care $[3,4]$ or with the addition of TENS [4]. However, this outcome measurement may be problematic as other factors influence the decision to use an epidural, such as the local culture at the delivery ward, the availability of an anaesthesiologist; or the woman's background [10]. In addition, the quality of midwife support influences the need of pharmacological pain relief [11]. As interventions such as acupuncture involve a high degree of midwifery presence, the possibility to draw proper conclusions from studies using such outcomes may be problematic. Other outcomes associated with conditions that may influence the experience of pain have also been evaluated but with contradictory results. In some studies, acupuncture increased the degree of relaxation $[4,9]$ while in others it did not $[5,7]$. In some it shortened the time spent in labour $[6,8]$, and in others it did not $[4,5,7,9]$.

Another important methodological aspect is the variation in intensity of treatment between the studies. Acupuncture with frequent manual stimulation seems to have a better effect on labour pain than treatments with less stimulation, such as minimal acupuncture [6, 8]. Also, high-intensity treatments, such as sterile water injections, seem to relieve pain more effectively than low-intensity acupuncture [5]. Previous studies therefore raise important questions that need to be explored further regarding acupuncture treatment such as type of stimulation (electrical versus manual), number of needles used, stimulation intensity, and treatment duration.

In addition to this, most previously published studies include small sample sizes, and few include power calculations assuring that the study is large enough to detect relevant differences in outcomes. The treatment protocol (i.e., a precise description of the treatment including number of acupuncture points used, stimulation type, frequency of sessions, and length of treatment period) is often incomplete or absent, and does not follow the CONSORT [12] recommendations for reporting RCT nor the STRICTA document [13], which is a complement for reporting acupuncture studies specifically. Differences in content of care in the control group and the inclusion and exclusion criteria all make the results difficult to evaluate. Some studies give limited or no information on important factors such as possible maternal and neonatal side effects, timing of the treatment, intensity of the treatment, and training and skills of the personnel administering the treatment $[3,6,7]$. Women receiving treatment from a small group of midwives who were experienced in administering acupuncture seemed to benefit more from treatment [8] than women who were treated by a large number of midwives with varying training and experience [5]. Information on biological markers of pain and stress may further increase the understanding of possible effects of acupuncture in the relief of labour pain.

Acupuncture involves puncturing the skin with thin sterile needles at well-defined acupuncture points which may be excitable muscle/skin-nerve complexes with a high density of nerve endings [14]. The needles are primarily stimulated manually or electrically. In manual acupuncture (MA) the needles are twisted back and forth until a feeling of DeQi is reached. DeQi is described as a sensation of numbness, soreness, or heaviness reflecting the activation of afferent nerve fibres. The efficacy of the treatment depends on its intensity, which is related to the number of times DeQi is reached $[15,16]$. In electroacupuncture (EA), needles are stimulated electrically [17]. Frequency and intensity are parameters known to influence the effect of EA.

The physiological mechanisms of acupuncture are not fully understood, but the pain-relieving effects may be explained by western medical theories [16]. Acupuncture needles activate receptors and afferent nerve fibres, in particular $\mathrm{A} \beta / \delta$-fibres and $\mathrm{C}$-fibres. According to Melzack and Wall, the stimulation of $\mathrm{A} \beta$-fibres activates the gate control mechanism that inhibits pain transmission at spinal level [18]. To activate these pain inhibiting systems, needles should be placed and stimulated in the same spinal segment as the source of the pain [19]. There are also extra segmental, central effects. Acupuncture triggers three main groups of opioid peptides, $\beta$-endorphin, enkephalin, and dynorphin [20]. Another effect of acupuncture is that it may activate another endorphin system-the diffuse noxious inhibitory Control (DNIC) system [21].

The nociceptive stimuli of the ripening and dilatation in the cervix in the initial stage of labour, known as the latent phase, are transmitted to the posterior root ganglia of thorasic spine Th10 to lumbar spine L1-L2. As the labour proceeds, more slowly in primiparous women than in multiparous, the nociceptive stimuli originate from the spinal segments S2-S4 [22, 23]. The nervous system, the immune system, and the endocrine system are all involved in the regulation of pain and the body's response to stress [24], and pain enhancement is mediated by glial activation and the release of proinflammatory cytokines [25]. Stressful experiences increase the circulation levels of proinflammatory cytokines [26], and possible associations between labour pain management, stress, and cytokines are underinvestigated.

Control interventions are a problem in acupuncture research [27] and the use of placebo has been discussed intensively $[28,29]$. Placebo interventions include minimal or superficial acupuncture, needles on nonacupuncture points (sham acupuncture), or "placebo needles", that is, needles with a handle that moves down over the needle, giving the false impression that they are inserted into the skin. A recent review demonstrates that placebo acupuncture differs from other physical and pharmacological placebo procedures in that it is associated with larger effects [30], possibly having a similar neurochemical basis with the activation of the endogenous opioid systems [19, 31], and sham acupuncture could be seen as a low-intensity form of therapeutic needling [27]. Consequently, placebo treatment does not seem to be a credible control intervention in acupuncture trials [19].

A review of previous studies indicates that acupuncture may have an effect on women's experiences of labour pain, but in order to enable a more definite conclusion further 
studies with better reporting to enable valid interpretations and replicability are needed.

\section{Aim and Outcome Measurements}

The aim of the present study was to evaluate the efficacy of two different acupuncture stimulations compared with standard care in the relief of labour pain. Our hypothesis is that acupuncture with manual or electrical stimulation is more effective than standard care in the relief of labour pain and that acupuncture with electrical stimulation is the most effective. This paper presents in-depth information on the design of the study and the ways in which we attempt to follow CONSORT [12] and STRICTA [13] recommendations.

\subsection{Primary Outcome. Experience of labour pain.}

\subsection{Secondary Outcomes}

Use of epidural analgesia.

Experience of relaxation.

Labour outcomes: mode of delivery, pain relief, augmentation of labour, duration of labour, and perineal trauma.

Negative side effects.

Experience of midwife support.

Proinflammatory cytokines, for example, interleukin (IL)-1, IL-6, highly sensitive C-reactive protein (hsCRP), and tumor necrosis (TNF)-alpha.

Memory of labour pain and overall childbirth experience.

Infant outcomes: Apgar score, $\mathrm{pH}, \mathrm{BE}$, and neonatal transfer.

\section{Materials and Methods}

3.1. Design. The study was designed as a three-armed, randomized, and controlled trial in two delivery wards in two different hospitals in Sweden. A description of the study outline is presented in Figure 1. All eligible women who gave their written consent to participate in the study were randomly allocated to one of three groups: manual acupuncture (MA), electroacupuncture (EA), or standard care (SC). The rationale of acupuncture was based on Western medical theories, and the study protocol follows CONSORT [12] and STRICTA [13] recommendations. The study is registered at ClinicalTrials.gov: NCT01197950. Process evaluation was conducted by intermittent checkups in order to assure that the intervention procedures were performed correctly and that they followed study protocol.

3.2. Participants. All nulliparous women who were in gestational week 34-36 and attended regular checkups with a midwife at the antenatal clinics connected to the two

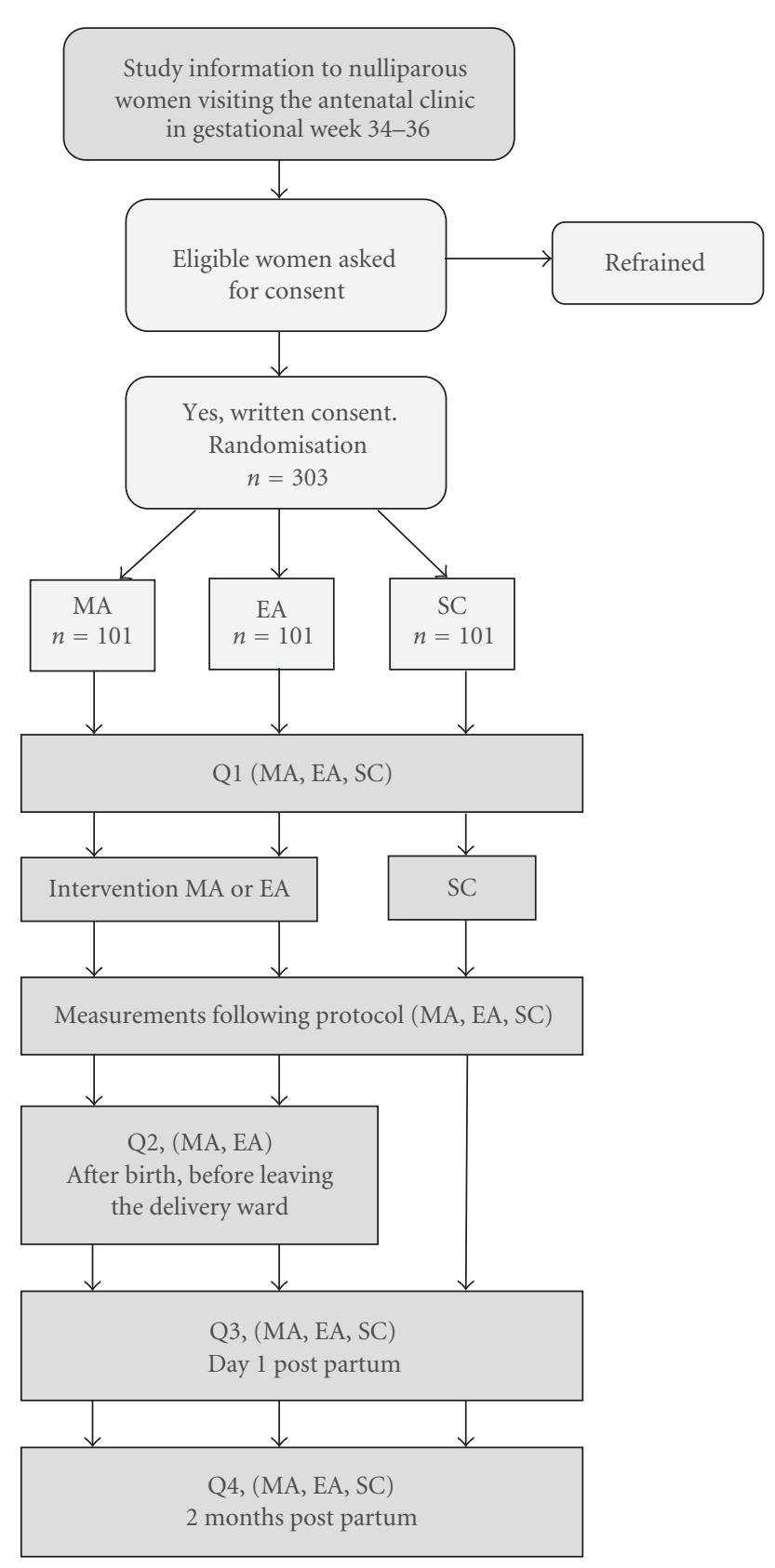

FIGURE 1: Study design including recruitment, randomization, interventions, and data collection. MA: Manual acupuncture, EA: Electroacupuncture, SC: Standard care, Q: Questionnaire.

hospitals received written and oral information about the study and an address to an informative study website (http://www.akupunkturstudien.se). Women were then asked to give consent to participate in the study when admitted to the labour ward.

\subsubsection{Inclusion Criteria}

Spontaneous onset of labour.

Admission to the labour ward in latent or active phase of labour. 
Nulliparity.

Singleton pregnancy, cephalic presentation.

Gestation: $37+0$ to $41+6$ (weeks + days).

Expressed need for labour pain relief.

Knowledge of the Swedish language good enough to understand written and oral instructions.

\subsubsection{Exclusion Criteria.}

Intake of pharmacological pain relief medication within 24 hours prior to inclusion into the study, with the exception of paracetamol.

Preeclampsia.

Treatment with oxytocin at the time point of allocation.

Treatment with anticoagulant.

Pacemaker.

After assessment of eligibility to the study, the women were randomized into one of the three groups. The randomization was conducted in blocks of 9,12 , and 15 , which were varied randomly. A computerised random number generator generated a list of codes from 1 to 303, with each code linked to one of the three groups. Sequentially numbered, opaque, sealed envelopes were prepared by one of the authors (LV), which included a study protocol and four questionnaires. At the time of allocation, the assisting midwife picked the envelope with the lowest number on which she wrote the participant's name and social security number and then opened it.

3.3. Education of Midwives. The participating midwives had varying training and experience of administering acupuncture treatment (Table 1). We therefore conducted a oneday study-specific course, which included theoretical sessions with a Western medical approach to acupuncture physiology, practical sessions in MA and EA, and lectures on research methodology with a focus on RCT. The course was repeated once every semester. The midwives at the antenatal clinics also received in-depth information about the study and the mechanisms of acupuncture. Furthermore, all midwives had access to the open website and, with the use of a password, access to a closed section that included instructional videos and written information about the study.

3.4. Interventions. All women in the trial received care from midwives throughout labour and birth and from obstetricians in cases of deviation from normal progress, according to Swedish clinical practice. All participants had access to all pharmacological and nonpharmacological analgesia available in Swedish maternity care with the exception of women in the SC group who did not have access to any form of acupuncture.

A list of acupuncture points based on literature and in collaboration with experienced clinicians and tutors was established (Table 2). Local points were selected in muscle
TABle 1: Participating midwives' previous education and experience with administrating acupuncture, prior to study training, $n=$ 38.

\begin{tabular}{lc}
\hline & $n$ \\
\hline Education prior to study training & 10 \\
One day course with a midwife at the delivery ward & \\
Practical focus with acupuncture points chosen on & \\
TCM basis & \\
Included neither acupuncture physiology nor EA & 14 \\
Five-day course with focus on TCM and WM & \\
Practical and theoretical sessions. \\
Acupuncture physiology based on both TCM and \\
WM \\
EA not included. \\
Six-day course in WM \\
Practical and theoretical sessions \\
Acupuncture physiology and research within the \\
area of acupuncture and obstetrics \\
EA included \\
No previous education in acupuncture at all \\
Experience of administrating acupuncture during \\
labour, prior to study \\
None \\
<1 year \\
$\begin{array}{l}\text { 1-2 years } \\
\text { 3-10 years } \\
\text { >10 years }\end{array}$ \\
\hline
\end{tabular}

TCM : traditional Chinese medicine, EA : electroacupuncture, WM : western medical acupuncture.

tissue in the pain area with the same somatic innervations as the cervix and uterus. In addition, points in hands and feet, so-called distal points, were selected in order to strengthen and prolong the effect of local needles. From the list, 3 bilateral distal points and 4-8 bilateral local points were chosen individually depending on pain location. In total, women in the MA and EA groups were treated with 13-21 needles. Sterile acupuncture Hegu Xeno needles for single use were used, sized $0.30 \times 30 \mathrm{~mm}$ and $0.35 \times 50 \mathrm{~mm}$. In the MA group, all needles were stimulated until DeQi was reached every ten minutes for a 40-minute period. In the EA group, all needles were stimulated manually until DeQi was reached, and then eight of the local needles were connected to an electrostimulator (Cefar Acus 4, CEFAR, Lund, Sweden) which was set at high-frequency stimulation $(80 \mathrm{~Hz})$ square wave pulses ( $0.18 \mathrm{~ms}$ duration) with alternating polarity. The woman adjusted the intensity of the electrical stimulation so it was just under their pain threshold. The remaining needles were stimulated manually by the midwife until DeQi was reached every ten minutes for a 40 -minute period. The needles were removed after 40 minutes in both groups. Two hours later the treatment was repeated. Additional treatment with MA or EA was thereafter available on request. After the first treatment with MA or EA, all women had access to standard forms of analgesia, if needed. 
TABLE 2: Acupuncture points used in the study.

\begin{tabular}{|c|c|c|c|}
\hline Points & Segmental innervation & Tissue & Depth (cun) \\
\hline \multicolumn{4}{|c|}{ Distal points } \\
\hline GV 20 & $\begin{array}{l}\text { Nn. trigeminus }(\mathrm{V}) \text {, occipitalis minor }(\mathrm{C} 2) \text {, } \\
\text { occipitalis major }(\mathrm{C} 2-3)\end{array}$ & Aponeurosis epicranii & $0.3-0.5$ \\
\hline LI 4 & Nn. medianus ulnaris (C8-Th1) & $\begin{array}{l}\text { Mm. interosseus dorsalis I, lumbricalis II, } \\
\text { adductor pollicis }\end{array}$ & $0.5-1$ \\
\hline SP 6 & N. tibialis (L4-S1) & Mm. flexor digitorum longus, tibialis posterior & $0.5-1$ \\
\hline LR 3 & N. plantaris lateralis (S2-3) & M. interosseus dorsalis I & $0.3-0.5$ \\
\hline PC6 & N. medianus (C8, Th1) & M. flexor digitorum superficialis & $0.5-0.8$ \\
\hline EX2 & N. trigeminus & M. frontalis & $0.3-0.5$ \\
\hline LU7 & N. cutaneus antebrachii lateralis (C5-6) & Fibrous tissue & $0.3-0.5$ \\
\hline \multicolumn{4}{|c|}{ Local points } \\
\hline SP 12 & N. thoracicus (Th7-12), lumbalis (L1) & $\begin{array}{l}\text { Aponeurosis mm. obliquus externus, abdominis } \\
\text { internus }\end{array}$ & $0.5-1$ \\
\hline BL 23 & $\begin{array}{l}\text { Nn. thoracodorsalis (C6-8), thoracicus (Th9-12), } \\
\text { lumbalis (L1-3) }\end{array}$ & $\begin{array}{l}\text { Mm. serratus posterior inferior, erector spinae, } \\
\text { fascia thoracolumbalis }\end{array}$ & $0.8-1$ \\
\hline BL 24 & $\begin{array}{l}\text { Nn. thoracodorsalis (C6-8), thoracicus (Th9-12), } \\
\text { lumbalis (L1-3) }\end{array}$ & Mm. erector spinae, fascia thoracolumbalis & $0.8-1$ \\
\hline BL 25 & $\begin{array}{l}\text { Nn. thoracodorsalis (C6-8), thoracicus (Th9-12), } \\
\text { lumbalis (L1-3) }\end{array}$ & Mm. erector spinae, fascia thoracolumbalis & $0.8-1$ \\
\hline BL 26 & $\begin{array}{l}\text { Nn. thoracodorsalis (C6-8), thoracicus (Th9-12), } \\
\text { lumbalis (L1-3) }\end{array}$ & Mm. erector spinae, fascia thoracolumbalis & $0.8-1$ \\
\hline BL 27 & $\begin{array}{l}\text { Nn. thoracodorsalis (C6-8), thoracicus (Th9-12), } \\
\text { lumbalis (L1-3) }\end{array}$ & Mm. erector spinae, fascia thoracolumbalis & $0.8-1$ \\
\hline BL 28 & $\begin{array}{l}\text { Nn. thoracodorsalis (C6-8), thoracicus (Th9-12), } \\
\text { lumbalis (L1-3) }\end{array}$ & Mm. erector spinae, fascia thoracolumbalis & $0.8-1$ \\
\hline BL 36 & N. gluteus inferior (L5-S2) & M. gluteus maximus & $1-1.5$ \\
\hline BL 54 & N. gluteus inferior & M. gluteus maximus & $1.5-2$ \\
\hline GB 25 & N. thoracicus (Th7-12) & M. obliquus externus abdominis & $0.3-0.5$ \\
\hline GB 26 & N. thoracicus (Th7-12) & M. obliquus externus abdominis & $0.5-0.8$ \\
\hline GB 27 & Nn. thoracicus lumbalis (Th7-L1) & $\begin{array}{l}\text { Aponeurosis mm. obliquus externus, internus } \\
\text { abdominis }\end{array}$ & $0.5-1$ \\
\hline GB 28 & M. obliquus externus abdominis & $\begin{array}{l}\text { Aponeurosis mm. obliquus externus, internus } \\
\text { abdominis }\end{array}$ & $0.5-1$ \\
\hline GB 29 & N. gluteus superior (L4-S1) & M. tensor fasciae latae & $0.5-1$ \\
\hline LR 10 & N. femoralis (L2-3) & M. pectineus & $0.5-1$ \\
\hline LR 11 & N. femoralis (L2-3) & M. pectineus & $0.5-1$ \\
\hline KI 11 & Nn. thoracicus (Th6-12), subcostalis (Th12) & $\begin{array}{l}\text { Mm. pyramidalis, rectus abdominis. Vagina } \mathrm{m} . \\
\text { recti abdominis }\end{array}$ & $0.5-1$ \\
\hline ST 29 & N. thoracicus (Th6-12) & M.rectus abdominis & $0.7-1.2$ \\
\hline CV3 & N. iliohypogastric (L1) & Fibrous tissue & $0.5-1$ \\
\hline $\mathrm{CV} 4$ & N. subcostalis (Th12) & Fibrous tissue & $0.5-1$ \\
\hline
\end{tabular}

GV: governor vessel channel, LI: large intestine channel, SP: spleen channel, LR: liver channel, PC: pericardium channel, EX: extra channel, LU: lung channel, BL: bladder channel, GB: gall bladder channel, KI: kidney channel, ST: stomach channel, CV: conception Vessel, Cun: traditional Chinese unit of length, 1 cun: width of the distal interphalangeal joint of the thumb.

3.5. Data Collection. Established study protocols were filled in by midwives throughout the labour, including details on the labour, the intervention, and maternal and neonatal outcomes and by the women when making their assessments of labour pain and relaxation on VAS (Table 3). Data were also collected from patient records and by means of questionnaires (Table 4).
3.6. Measuring Pain and Relaxation. VAS was used for assessing experience of labour pain and relaxation. VAS is a $100 \mathrm{~mm}$ horizontal ungraded line with two endpoints: "no pain" (left) and "worst pain imaginable" (right) and "relaxed" (left) and "very tense" (right). Each woman assessed her level of pain/relaxation by making a vertical mark on the line with a sharp pencil [37]. VAS has been 
TABLE 3: Content of study protocol, similar for all groups.

\begin{tabular}{|c|c|}
\hline Concept & Measurement and response alternatives \\
\hline \multicolumn{2}{|l|}{ Mother } \\
\hline Pain during contraction & VAS, every 30 minutes for 5 hours, and then every hour until birth \\
\hline Relaxation during contraction & VAS, every 30 minutes for 5 hours, and then every hour until birth \\
\hline Pain localisation & $\begin{array}{l}\text { Back/Abdomen/Groin. } \\
\text { every } 30 \text { minutes for } 5 \text { hours, and then every hour until birth }\end{array}$ \\
\hline Cervix dilatation and length & $\begin{array}{l}\mathrm{Cm} \\
3 \text { times during } 5 \text { hours }\end{array}$ \\
\hline Contractions (duration/interval) & $\begin{array}{l}\text { Seconds/Minutes } \\
5 \text { times during } 5 \text { hours }\end{array}$ \\
\hline Details of intervention & $\begin{array}{l}\text { Point selection from Table 2, duration of treatment, stimulation } \\
\text { technique and stimulation frequency }\end{array}$ \\
\hline Additional pain relief & $\begin{array}{l}\text { Sterile water injections/TENS/Entonox/Opioid epidural and } \\
\text { intrathecal analgesia/Pudendal nerve block/Paracervical block/Other }\end{array}$ \\
\hline $\begin{array}{l}\text { Midwives's evaluation of the treatment effect for pain relief } \\
\text { and relaxation (MA and EA) }\end{array}$ & Very effective/Fairly effective/Not so effective/Not effective at all \\
\hline Negative side effects (EA, MA) & Yes, if so, a description of the side effects/No \\
\hline Augmentation of labour & Yes, if so, indication primary and secondary dystocia, other/No \\
\hline Rupture of membranes/Amniotomy & Date/Time \\
\hline Partus & Date/Time \\
\hline Mode of delivery & $\begin{array}{l}\text { Vaginal delivery/Vacuum extraction/Forceps/Emergency caesarean } \\
\text { section }\end{array}$ \\
\hline Perineal injury & Degree I-IV \\
\hline \multicolumn{2}{|l|}{ Infant } \\
\hline Apgar score & 1,5 and $10 \mathrm{~min}$ \\
\hline Birth weight & Grams \\
\hline Arterial and venous blood gases & pH/Base Excess (umbilical cord samples) \\
\hline Neonatal transfer & $\mathrm{Yes} / \mathrm{No}$ \\
\hline
\end{tabular}

VAS: visual analogue scale, TENS: transcutaneous electrical nerve stimulation, MA: manual acupuncture, EA: electroacupuncture.

shown to be valid in detecting changes in pain intensity $[38,39]$ and relaxation $[5,7,9,40]$, and most individuals have no difficulties using it $[38,41]$. One problem, however, is that the suitability of using VAS for monitoring labour pain has been questioned, as it has an apparent problem with response shift. As the labour proceeds, the pain intensity increases, and there is a possibility that the meaning of a value on VAS is changed (recalibrated) due to the higher pain intensity [42]. Although there are problems with using VAS to assess labour pain, it is currently the most common and best-validated pain scale used in research into labour pain. The measurements were conducted before the first treatment, immediately after the first treatment and then every 30 minutes for five hours and thereafter every hour until birth or until an epidural was administered. A different person from the one who administered the intervention (help nurse or midwife) assisted the women in the procedure of measuring pain and relaxation, however; blinding was not possible.

3.7. Questionnaires. Questionnaires were answered before the first treatment (Q1), immediately after birth (Q2), the day after birth (Q3), and two months later (Q4) (Table 4). Q1 asked about social-demographic background, previous experience of acupuncture, experience of menstrual pain, and how painful the woman expected the upcoming birth to be. Q2 was answered by women in the MA and EA groups only and included questions regarding experience of the acupuncture treatment, effects of the treatment, and negative side effects, if any. Q3 and Q4 were answered by all participants and asked about experience of labour $[5,34,43-$ 45], pain relief, memory of labour pain measured by VAS, experience of the intervention, support during labour, and emotional health problems in terms of depressive symptoms, which were assessed by the Edinburgh Postnatal Depression Scale $[35,36]$. All protocols and questionnaires were pilot tested.

3.8. Blood Sampling. Blood samples were collected in the MA and EA groups before the first treatment and directly after the first treatment and in the SC group, before the first analgesic treatment and 30 minutes later. An indwelling intravenous catheter was inserted, and from this $5 \mathrm{~mL}$ of blood was drawn and collected in a standard tube. The samples clotted for a minimum of 30 minutes and no longer than four hours before they were centrifuged at $3000 \mathrm{rpm}$ for 15 minutes at $20^{\circ} \mathrm{C}$. Four polypropylene tubes of $0.5 \mathrm{~mL}$ with aliquots of serum and plasma were frozen at minus 
TABLE 4: Content of questionnaires, before treatment (Q1), and postnatal questionnaires (Q2-Q4).

Concept
Previous acupuncture experience
Dysmenorrhea
Worry of pain in daily life*
Worry of labour pain*
Sociodemographic background
Postnatal valuation of treatment effect on pain and
relaxation (MA and EA)
Use this treatment again? (EA, MA)
Negative side effects (EA, MA)
Prelabour worries for: (a) labour pain*, (b) not enough
pain relief, (c) not enough support from midwife
Support from midwife during labour
Overall experience of pain during labour
Overall experience of relaxation during labour
Experienced labour pain in relation to expected**

Assessment of midwife's acupuncture skills (EA, MA)

Overall assessment of pain relief

Sufficiency of pain relief

Emotions during labour*

Emotions during labour, overall

Perception of the midwife*

Overall perception of the midwife

Why participate in this study?

Satisfaction with the allocation.

Overall birth experience ${ }^{\dagger}$

Depressive symptoms

Experience of participating in this study

\begin{tabular}{|c|c|}
\hline Response alternative & Questionnaire \\
\hline Yes for pain/Yes for other than pain/No & Q1 \\
\hline Yes, if so, estimation on VAS/No & Q1 \\
\hline $\begin{array}{l}\text { Not at all worried/Not very worried/Quite worried/Very } \\
\text { worried }\end{array}$ & Q1 \\
\hline $\begin{array}{l}\text { Not at all worried/Not very worried/Quite worried/Very } \\
\text { worried }\end{array}$ & Q1 \\
\hline Education/Ancestral homeland/Parents citizenship & Q1 \\
\hline $\begin{array}{l}\text { Very effective/Rather effective/Not very effective/Not } \\
\text { effective at all }\end{array}$ & Q2, Q3, Q4 \\
\hline Yes/No & Q2, Q3, Q4 \\
\hline Yes, if so, description of side effects/No & Q2, Q3, Q4 \\
\hline $\begin{array}{l}\text { Not at all worried/Not very worried/Quite worried/Very } \\
\text { worried }\end{array}$ & Q3 \\
\hline $\begin{array}{l}\text { Yes to a high extent/Yes to a rather high extent/No to a } \\
\text { rather low extent/No not at all }\end{array}$ & Q3, Q4 \\
\hline VAS & Q3, Q4 \\
\hline VAS & Q3, Q4 \\
\hline $\begin{array}{l}\text { Much more severe than expected/More severe than } \\
\text { expected/As expected/Milder than expected/Much milder } \\
\text { than expected }\end{array}$ & Q3, Q4 \\
\hline $\begin{array}{l}\text { Very competent/Quite competent/Not very } \\
\text { competent/Not competent at all }\end{array}$ & Q3, Q4 \\
\hline $\begin{array}{l}\text { Very effective/Rather effective/Not very effective/Not } \\
\text { effective at all }\end{array}$ & Q3, Q4 \\
\hline Enough/Not enough & Q3, Q4 \\
\hline $\begin{array}{l}\text { Strong/Weak/Happy/Sad/Calm/ Frightened/Alert/ } \\
\text { Tired/Secure/Worried/Involved/Lonely/ } \\
\text { Detached/Independent/Empowered/ } \\
\text { Abandoned/Determined/Tense/Trust in my own } \\
\text { capacity/Challenged/Focused/Panic/Disappointed/Present }\end{array}$ & Q3, Q4 \\
\hline Positive/Negative & Q3, Q4 \\
\hline $\begin{array}{l}\text { Calm/Rushed/Supportive/Unhelpful/Clear/ } \\
\text { Incompetent/Rude/Humorous/Inconsiderate/Sensitive/ } \\
\text { Bossy/Absent/Warm/Nonchalant/Secure/Condescending/ } \\
\text { Considerate/Competent/Vague/Informative/ } \\
\text { Insensitive/Supportive }\end{array}$ & Q3, Q4 \\
\hline Positive/Negative & Q3, Q4 \\
\hline Open-ended & Q3 \\
\hline $\begin{array}{l}\text { Yes satisfied/No, if so, which allocation would you have } \\
\text { preferred? }\end{array}$ & Q3 \\
\hline $\begin{array}{l}\text { Very positive/Positive/Mixed feelings/Negative/Very } \\
\text { negative }\end{array}$ & Q3, Q4 \\
\hline Edinburgh Postnatal Depression Scale ${ }^{\dagger \dagger}$ & Q4 \\
\hline Positive/Negative & Q4 \\
\hline
\end{tabular}

Q1-4: questionnaire 1-4, VAS: visual analogue scale, MA: manual acupuncture, EA: electroacupuncture.

${ }^{*}$ Schytt et al. [32], adjusted for this study, ${ }^{* *}$ Experience of pregnancy and delivery, the women's perspective [33], ${ }^{\dagger}$ Waldenström [34], ${ }^{\dagger \dagger}$ Wickberg and Hwang [35], and Murray and Carothers [36].

$70^{\circ} \mathrm{C}$. Proinflammatory cytokines, for example, interleukin (IL)-1, IL-6, highly sensitive C-reactive protein (hs-CRP), and tumour necrosis (TNF)-alpha, will later be analysed by commercial assays at an accredited laboratory.

3.9. Sample Size Calculation. The sample size calculation was based on the primary outcome measure, experience of labour pain. The calculation used a Bonferroni adjusted significant level of 0.017 and a power of 0.80. A standard deviation of $20.4 \mathrm{~mm}$ on the VAS displayed in each group was brought from historical data [9]. To detect a difference of $15 \mathrm{~mm}$ on VAS between the three groups, 41 women in each group were needed. However, a previous study [5] shows that a high internal dropout could be expected 
because of labour-related factors, such as an inability to carry through the measurements due to pain or that birth has occurred. Two hours after the first treatment, only $47 \%$ of the women had registered data on pain or relaxation (personal communication Dr. L. B. Mårtensson January 2008). To compensate for this expected dropout rate, 88 women in each group were needed. Finally, another 15\% dropout due to women's dissatisfaction with the randomization or midwives' high workload could be expected. This required a total of 101 women in each group, that is, 303 women in total.

3.10. Statistical Analyses. A problem with analyses of longitudinal data, is that repeated observations for the same individual are often correlated. This correlation violates the assumption of independence necessary for more-traditional, repeated-measures analysis and leads to bias in regression parameters. To avoid this problem we intend to use a mixed effects models approach in the analysis. Typically, ignoring the correlation of observations leads to smaller standard errors (SEs) and increases type I errors which might lead to the wrong conclusion $[46,47]$. Furthermore, the analysis of mixed effect models enables to handle missing data as well as the integration of time-varying factors, such as cervical dilatation, which are issues in the present study.

\section{Ethical Considerations}

The study has no foreseeable risks but may cause minor discomfort in the form of tiredness or minor bruising. The women were informed that (1) participation in the study was voluntary, (2) their decision whether or not to participate would not affect their current or future treatment, (3) if they decided to participate they were free to withdraw at any time, and (4) all questionnaires and blood samples would be unidentified. The women who agreed to participate in the study signed a consent form. The study was approved by the Regional Ethical Review Board, University of Gothenburg, 2008-05-15, Dnr: 136-08.

\section{Summary}

Since the evidence of the effect of acupuncture on labour pain is nonconclusive or lacking, possibly because of methodological reasons, there is a need for more welldesigned studies, and this study intends to fill such a gap by avoiding some of the limitations of previous research. Many women would like to have nonpharmacological pain relief during labour, and acupuncture is one such treatment that is available in all delivery units in Sweden. However, if acupuncture is not proven to be effective, it should not be recommended for labour pain, which is possibly the most intensive pain a woman may ever experience.

\section{Acknowledgments}

The authors would like to thank Professor Ulla Waldenström, Karolinska Institutet, and Professor Ove Axelsson, Uppsala University for their contribution to the design of the study and Jacob Bergström and Hans Pettersson, Karolinska Institutet for their helpful advice on statistics. This study is funded by grants from Centre for Clinical Research Dalarna, Karolinska Institutet, Uppsala-Örebro Regional Research Council, University of Skövde, FOU Fyrbodal, Magnus Bergvall Stiftelse, and Dalarna University, Sweden.

\section{References}

[1] S. Birch, "Clinical research on acupuncture: part 2. Controlled clinical trials, an overview of their methods," Journal of Alternative and Complementary Medicine, vol. 10, no. 3, pp. 481-498, 2004.

[2] S. H. Cho, H. Lee, and E. Ernst, "Acupuncture for pain relief in labour: a systematic review and meta-analysis," BJOG: An International Journal of Obstetrics and Gynaecology, vol. 117, no. 8, pp. 907-920, 2010.

[3] B. I. Nesheim, R. Kinge, B. Berg et al., "Acupuncture during labor can reduce the use of meperidine: a controlled clinical study," Clinical Journal of Pain, vol. 19, no. 3, pp. 187-191, 2003.

[4] L. Borup, W. Wurlitzer, M. Hedegaard, U. S. Kesmodel, and L. Hvidman, "Acupuncture as pain relief during delivery: a randomized controlled trial," Birth, vol. 36, no. 1, pp. 5-12, 2009.

[5] L. Mårtensson, E. Stener-Victorin, and G. Wallin, "Acupuncture versus subcutaneous injections of sterile water as treatment for labour pain," Acta Obstetricia et Gynecologica Scandinavica, vol. 87, no. 2, pp. 171-177, 2008.

[6] S. Hantoushzadeh, N. Alhusseini, and A. H. Lebaschi, "The effects of acupuncture during labour on nulliparous women: a randomised controlled trial," Australian and New Zealand Journal of Obstetrics and Gynaecology, vol. 47, no. 1, pp. 2630, 2007.

[7] S. Ziaei and L. Hajipour, "Effect of acupuncture on labor," International Journal of Gynecology and Obstetrics, vol. 92, no. 1, pp. 71-72, 2006.

[8] E. Skilnand, D. Fossen, and E. Heiberg, "Acupuncture in the management of pain in labor," Acta Obstetricia et Gynecologica Scandinavica, vol. 81, no. 10, pp. 943-948, 2002.

[9] A. Ramnerö, U. Hanson, and M. Kihlgren, "Acupuncture treatment during labour-a randomised controlled trial," BJOG: An International Journal of Obstetrics and Gynaecology, vol. 109, no. 6, pp. 637-644, 2002.

[10] E. Schytt and U. Waldenstrm, "Epidural analgesia for labor pain: whose choice?" Acta Obstetricia et Gynecologica Scandinavica, vol. 89, no. 2, pp. 238-242, 2010.

[11] E. D. Hodnett, S. Gates, G. J. Hofmeyr, and C. Sakala, "Continuous support for women during childbirth," Cochrane Database of Systematic Reviews (Online), no. 3, Article ID CD003766, 2011.

[12] D. Moher, S. Hopewell, K. F. Schulz et al., "CONSORT 2010 explanation and elaboration: updated guidelines for reporting parallel group randomised trials," BMJ: British Medical Journal, vol. 340, no. 1, article c869, 2010.

[13] H. Macpherson, D. G. Altman, R. Hammerschlag et al., "Revised standards for reporting interventions in clinical trials of acupuncture (stricta): extending the consort statement," PLoS Medicine, vol. 7, no. 6, article e1000261, 2010.

[14] A. H. Li, J. M. Zhang, and Y. K. Xie, "Human acupuncture points mapped in rats are associated with excitable muscle/skin-nerve complexes with enriched nerve endings," Brain Research, vol. 1012, no. 1-2, pp. 154-159, 2004. 
[15] K. K. S. Hui, J. Liu, O. Marina et al., "The integrated response of the human cerebro-cerebellar and limbic systems to acupuncture stimulation at ST 36 as evidenced by fMRI," NeuroImage, vol. 27, no. 3, pp. 479-496, 2005.

[16] Z. Q. Zhao, "Neural mechanism underlying acupuncture analgesia," Progress in Neurobiology, vol. 85, no. 4, pp. 355-375, 2008.

[17] V. V. Romita, A. Suk, and J. L. Henry, "Parametric studies on electroacupuncture-like stimulation in a rat model: effects of intensity, frequency, and duration of stimulation on evoked antinociception," Brain Research Bulletin, vol. 42, no. 4, pp. 289-296, 1997.

[18] R. Melzack and P. D. Wall, "Pain mechanisms: a new theory," Science, vol. 150, no. 3699, pp. 971-979, 1965.

[19] D. Pyne and N. G. Shenker, "Demystifying acupuncture," Rheumatology, vol. 47, no. 8, pp. 1132-1136, 2008.

[20] S. M. Wang, Z. N. Kain, and P. White, "Acupuncture analgesia: I. The scientific basis," Anesthesia and Analgesia, vol. 106, no. 2, pp. 602-610, 2008.

[21] D. Le Bars, A. H. Dickenson, and J. M. Besson, "Diffuse noxious inhibitory controls (DNIC). II. Lack of effect on nonconvergent neurones, supraspinal involvement and theoretical implications," Pain, vol. 6, no. 3, pp. 305-327, 1979.

[22] B. K. Tingåker, Changes in human uterine innervation in term pregnancy and labor: occurence and roles of neurotrophins and TRPV1, Dissertation, Karolinska Institutet, Stockholm, Sweden, 2008.

[23] N. K. Lowe, "The nature of labor pain," American Journal of Obstetrics and Gynecology, vol. 186, no. 5, supplement, pp. S16-S24, 2002.

[24] C. R. Chapman, R. P. Tuckett, and C. W. Song, "Pain and stress in a systems perspective: reciprocal neural, endocrine, and immune interactions," Journal of Pain, vol. 9, no. 2, pp. 122-145, 2008.

[25] J. Wieseler-Frank, S. F. Maier, and L. R. Watkins, "Immuneto-brain communication dynamically modulates pain: physiological and pathological consequences," Brain, Behavior, and Immunity, vol. 19, no. 2, pp. 104-111, 2005.

[26] M. Altemus, B. Rao, F. S. Dhabhar, W. Ding, and R. D. Granstein, "Stress-induced changes in skin barrier function in healthy women," Journal of Investigative Dermatology, vol. 117, no. 2, pp. 309-317, 2001.

[27] A. White and M. Cummings, "Does acupuncture relieve pain?” BMJ, vol. 338, no. 7690, pp. 303-304, 2009.

[28] S. Birch, "A review and analysis of placebo treatments, placebo effects, and placebo controls in trials of medical procedures when sham is not inert," Journal of Alternative and Complementary Medicine, vol. 12, no. 3, pp. 303-310, 2006.

[29] T. Lundeberg, I. Lund, J. Näslund, and M. Thomas, "The Emperor's sham-wrong assumption that sham needling is sham," Acupuncture in Medicine, vol. 26, no. 4, pp. 239-242, 2008.

[30] K. Linde, K. Niemann, and K. Meissner, "Are sham acupuncture interventions more effective than (other) placebos? A reanalysis of data from the cochrane review on placebo effects," Forschende Komplementarmedizin, vol. 17, no. 5, pp. 259-264, 2010.

[31] C. S. Greene, G. Goddard, G. M. Macaluso, and G. Mauro, "Topical review: placebo responses and therapeutic responses. How are they related?" Journal of Orofacial Pain, vol. 23, no. 2, pp. 93-107, 2009.

[32] E. Schytt, J. M. Green, H. A. Baston, and U. Waldenstrom, "A comparison of Swedish and English primiparae's experiences of birth," Journal of Reproductive and Infant Psychology, vol. 26, no. 4, pp. 277-294, 2008.

[33] "Experience of pregnancy and delivery-the women's perspective," http://ki.se/ki/jsp/polopoly.jsp?l=en\&d=24390.

[34] U. Waldenström, "Women's memory of childbirth at two months and one year after the birth," Birth, vol. 30, no. 4, pp. 248-254, 2003.

[35] B. Wickberg and C. P. Hwang, "The Edinburgh Postnatal Depression Scale: validation on a Swedish community sample," Acta Psychiatrica Scandinavica, vol. 94, no. 3, pp. 181184, 1996.

[36] L. Murray and A. D. Carothers, "The validation of the Edinburgh Post-natal Depression Scale on a community sample," British Journal of Psychiatry, vol. 157, pp. 288-290, 1990.

[37] E. Huskisson, "Visual analogue scales," in Pain Measurement and Assesment, R. Melzack, Ed., vol. 293, Raven, New York, NY, USA, 1983.

[38] M. Choiniere, R. Melzack, N. Girard, J. Rondeau, and M. J. Paquin, 'Comparisons between patients' and nurses' assessment of pain and medication efficacy in severe burn injuries," Pain, vol. 40, no. 2, pp. 143-152, 1990.

[39] C. R. B. Joyce, D. W. Zutshi, V. Hrubes, and R. M. Mason, "Comparison of fixed interval and visual analogue scales for rating chronic pain," European Journal of Clinical Pharmacology, vol. 8, no. 6, pp. 415-420, 1975.

[40] J. Hattan, L. King, and P. Griffiths, "The impact of foot massage and guided relaxation following cardiac surgery: a randomized controlled trial," Journal of Advanced Nursing, vol. 37, no. 2, pp. 199-207, 2002.

[41] M. P. Jensen, P. Karoly, and S. Braver, "The measurement of clinical pain intensity: a comparison of six methods," Pain, vol. 27, no. 1, pp. 117-126, 1986.

[42] R. Barclay-Goddard, J. D. Epstein, and N. E. Mayo, "Response shift: a brief overview and proposed research priorities," Quality of Life Research, vol. 18, no. 3, pp. 335-346, 2009.

[43] J. M. Green and H. A. Baston, "Feeling in control during labor: concepts, correlates, and consequences," Birth, vol. 30, no. 4, pp. 235-247, 2003.

[44] I. M. Hildingsson, "New parents' experiences of postnatal care in Sweden," Women and Birth, vol. 20, no. 3, pp. 105-113, 2007.

[45] U. Waldenström and E. Schytt, "A longitudinal study of women's memory of labour pain-from 2 months to 5 years after the birth," BJOG: An International Journal of Obstetrics and Gynaecology, vol. 116, no. 4, pp. 577-583, 2009.

[46] R. Gueorguieva and J. H. Krystal, "Move over ANOVA: progress in analyzing repeated-measures data and its reflection in papers published in the archives of general psychiatry," Archives of General Psychiatry, vol. 61, no. 3, pp. 310-317, 2004.

[47] H. Brown and R. Prescott, Applied Mixed Models in Medicine, Oxford University Press, New York, NY, USA, 1999. 


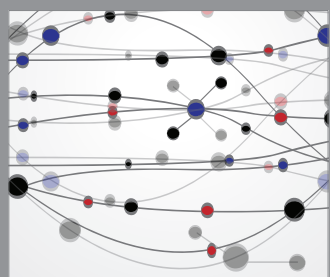

The Scientific World Journal
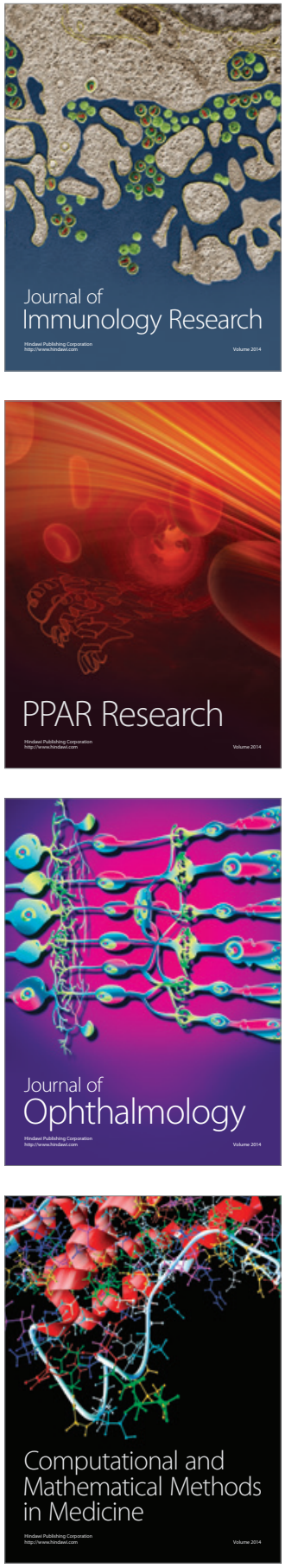

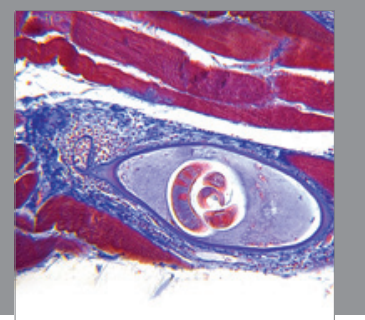

Gastroenterology

Research and Practice
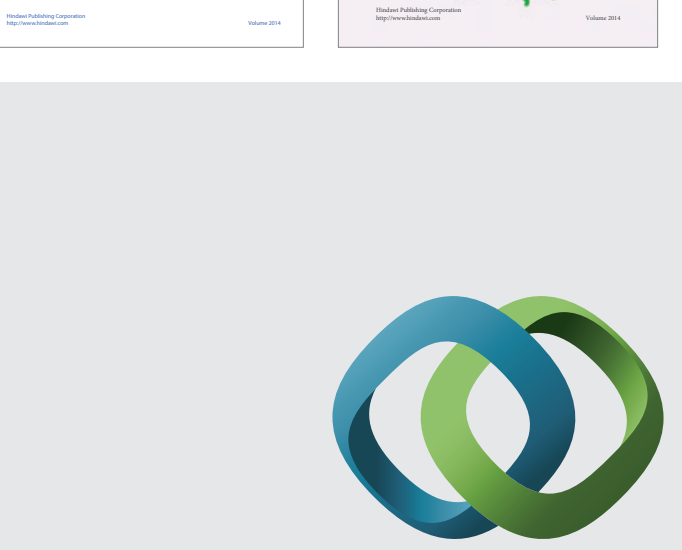

\section{Hindawi}

Submit your manuscripts at

http://www.hindawi.com
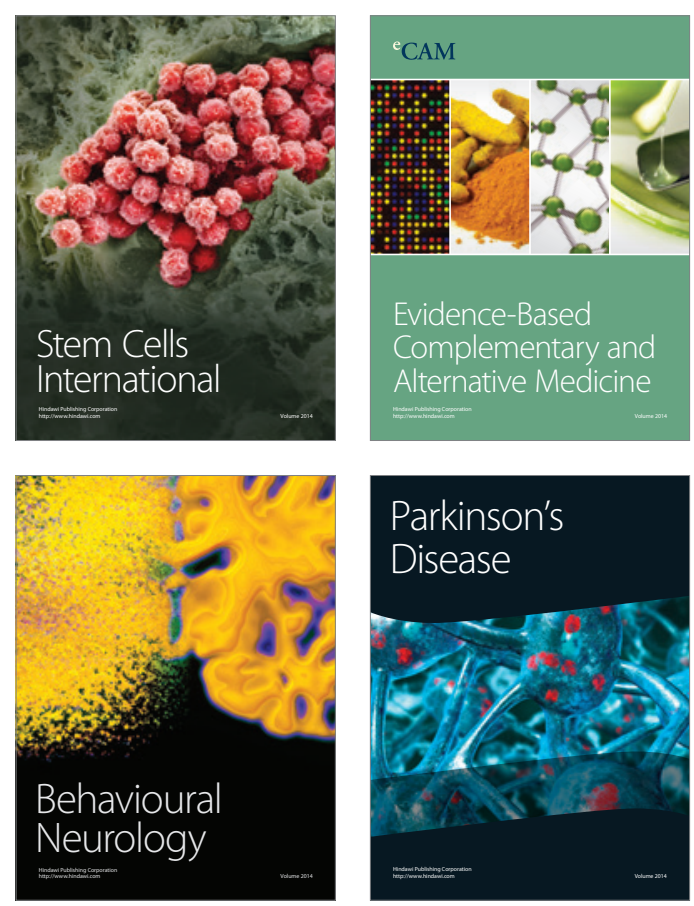

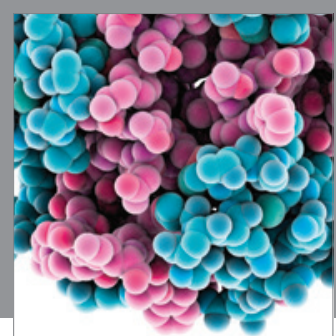

Journal of
Diabetes Research

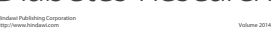

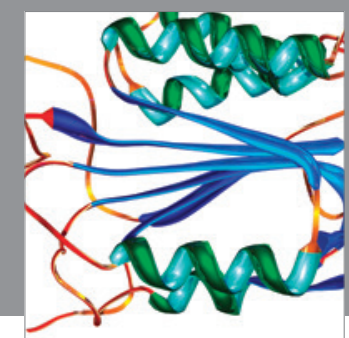

Disease Markers
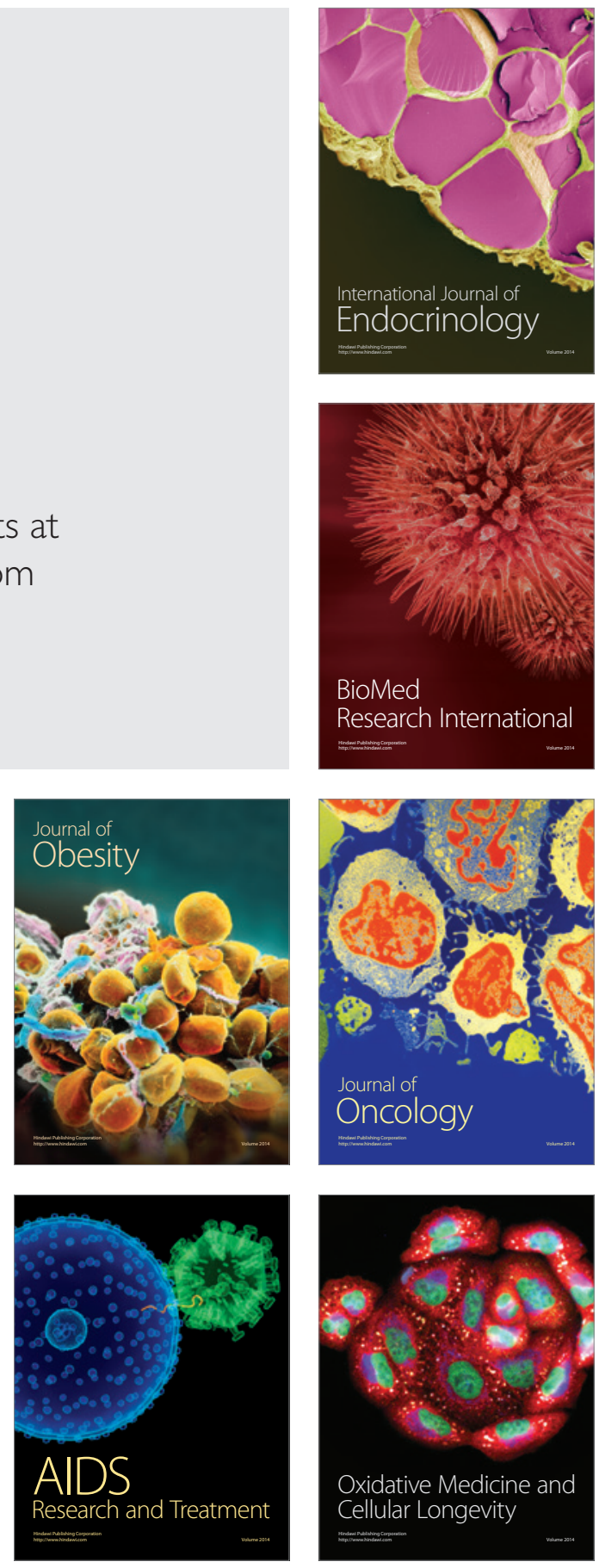